Provided for non-commercial research and education use. Not for reproduction, distribution or commercial use.

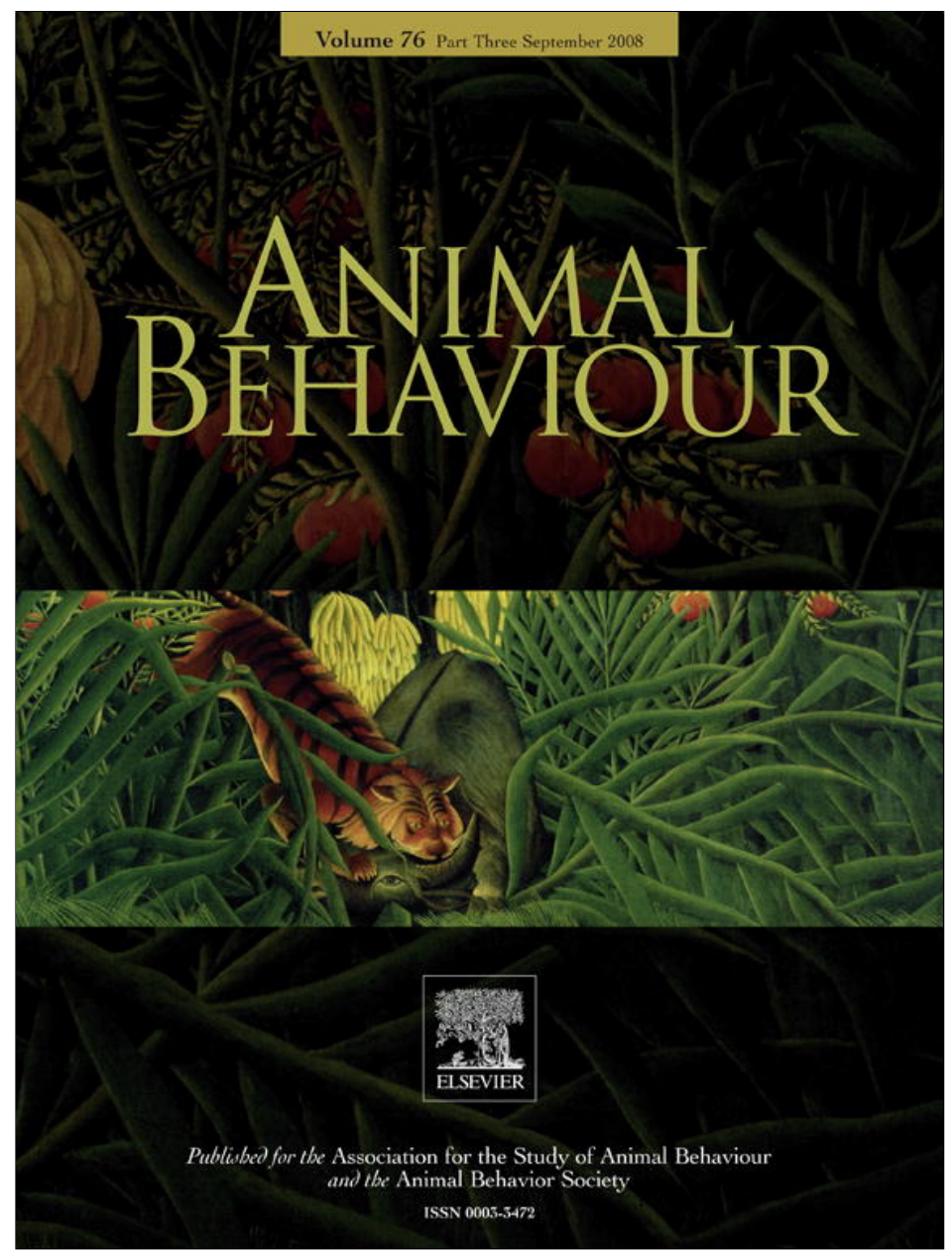

This article appeared in a journal published by Elsevier. The attached copy is furnished to the author for internal non-commercial research and education use, including for instruction at the authors institution and sharing with colleagues.

Other uses, including reproduction and distribution, or selling or licensing copies, or posting to personal, institutional or third party websites are prohibited.

In most cases authors are permitted to post their version of the article (e.g. in Word or Tex form) to their personal website or institutional repository. Authors requiring further information regarding Elsevier's archiving and manuscript policies are encouraged to visit:

http://www.elsevier.com/copyright 


\title{
Double-blind peer review and gender publication bias
}

\author{
LEIF ENGQVIST \& JOACHIM G. FROMMEN \\ Department of Evolutionary Biology and Ecology, University of Bonn \\ (Received 28 March 2008; initial acceptance 5 May 2008; \\ final acceptance 25 May 2008; published online 9 July 2008; MS. number: D-08-00215)
}

Keywords: effect size; gender bias; GLMM; refereeing process; sex difference

A researcher's publication record is frequently used as a measure of scientific merit. Unfortunately though, factors other than the scientific quality of a manuscript (such as gender or nationality) often influence the probability of acceptance (Wennerås \& Wold 1997; Link 1998; Tregenza 2002). Bias in the refereeing process is thus a major concern throughout the scientific community. The double-blind review process, where both authors and referees are anonymous, might prevent some of these problems associated with publication bias. However, the usefulness of such double-blind reviews is frequently discussed (Anon 2008; Garvalov 2008; Lane 2008; Naqvi 2008; O'Hara 2008).

In a recent article, Budden et al. (2008) claimed that double-blind review is associated with an increased representation of female authors. They found that the journal Behavioral Ecology (BE) has published significantly more articles with female first authors since it changed its policy and initiated double-blind review in 2001. However, an increase in the proportion of female authors could not be found in similar journals that during the same period of time continued to practise single-blind review (Animal Behaviour (AB), Behavioral Ecology and Sociobiology (BES), Journal of Biogeography (JB), and Landscape Ecology (LE)). In a further journal (Biological Conservation, BC) that does not practise double-blind review, female representation also increased significantly. Here Budden et al. (2008) argued that the increase in female first authors was the result of an increased number of submissions by females. They concluded that double-blind review could weaken gender biases in the review process of manuscripts. However, the proportion of female authors increased in almost all journals sampled irrespective of review policy (Fig. 1), although this change was significant

Correspondence: L. Engqvist, Department of Evolutionary Biology and Ecology, University of Bonn, An der Immenburg 1, 53121 Bonn, Germany (email: lengqvist@evolution.uni-bonn.de). only in $\mathrm{BE}$ and $\mathrm{BC}(P<0.05)$. Unfortunately, finding a significant effect in one sample but not in a different sample does not answer the crucial question whether the two samples actually differ. Instead one needs to compare and test differences in effect sizes.

We therefore reanalysed the data by using a generalized mixed-effect approach (GLMM), with a model including the fixed factors time of publication (before or after an eventual change in review policy) and review practice (change or no change), the random factor journal and the dependent variable author gender (female, male). A significant time of publication*review practice interaction would indicate that the rate of increase in the proportion of female authors is affected by a change in journal peer review practice. We could not verify this effect with these data $\left(\chi_{1}^{2}=1.54, P=0.22\right)$. Moreover, the change in the proportion of female first authors in BE since it changed review policy did not differ significantly from the change in proportion of female first authors in any of the other journals during the same period (BE versus BES: $\chi_{1}^{2}=1.94$, $P=0.13$; BE versus $\mathrm{AB}: \chi_{1}^{2}=1.14, P=0.29$; $\mathrm{BE}$ versus $\mathrm{BC}$ : $\chi_{1}^{2}=0.02, \mathrm{P}=0.89 ; \mathrm{BE}$ versus $\mathrm{JB}: \chi_{1}^{2}=3.19, P=0.07 ; \mathrm{BE}$ versus LE: $\left.\chi_{1}^{2}=0.03, P=0.85\right)$. These results become even less significant after Bonferroni correction for multiple testing with a reduced $\alpha$ level of 0.008 . Nevertheless, the analyses do show, and this is welcome news, that the proportion of articles first-authored by females has, overall, increased significantly $\left(\chi_{3}^{2}=27.7, P<0.0001\right.$; Fig. 1$)$.

An additional problem with Budden et al.'s (2008) analysis is that the proportion of female authors in the respective journals was initially very different. For instance, before changing the review practice to double-blind review, $B E$ had a significantly lower proportion of female first authors than $\mathrm{AB}\left(\chi_{1}^{2}=4.74, P=0.03\right)$. It is therefore not very surprising to find a somewhat stronger increase in female authorship in the former journal.

Summarizing, we absolutely do not refute the fact that review behaviour can be affected by the gender of the 


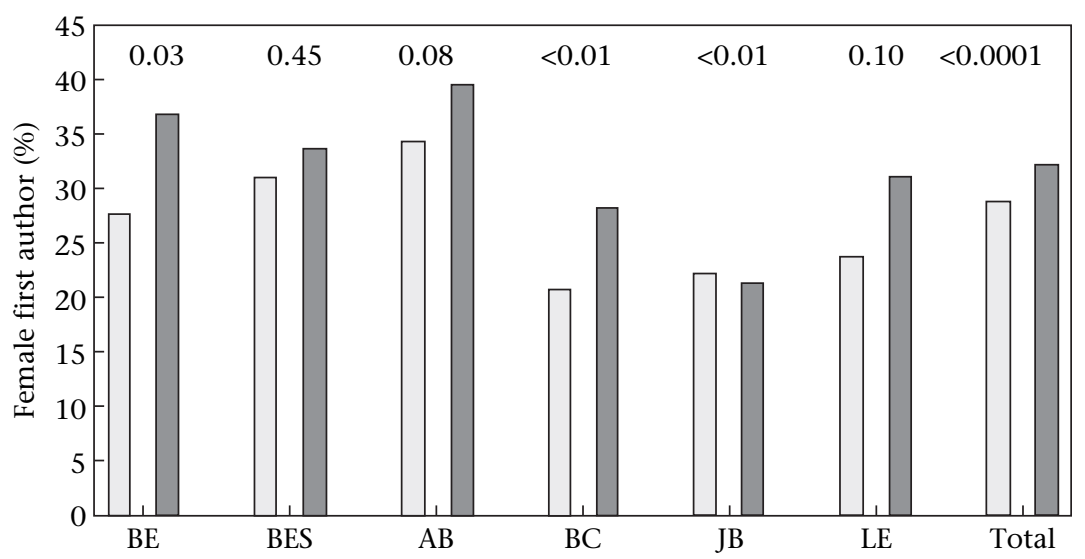

Figure 1. Percentage of female first authors in the years 1997-2000 (light bars) and 2002-2005 (dark bars). See text for abbreviations of journals. Numbers above the bars represent for each journal the $P$ values for the comparison between the years of publication.

author (Link 1998; Tregenza 2002; Budden et al. 2008). Yet our reanalysis could not confirm that double-blind review has any detectable positive effect. It is thus simply too premature to conclude that the representation of female authors is favoured by a double-blind review process. We believe that more target-oriented actions are needed to facilitate the scientific careers of female scientists, especially at young ages.

We are grateful to Theo Bakker, Louise Barrett and two anonymous referees for comments on the manuscript and to Manila Engqvist and Julia Schwarzer for discussion.

\section{References}

Anon. 2008. Working double-blind. Nature, 451, 605-606.
Budden, A. E., Tregenza, T., Aarssen, L. W., Koricheva, J., Leimu, R. \& Lortie, C. J. 2008. Double-blind review favours increased representation of female authors. Trends in Ecology \& Evolution, 23, 4-6.

Garvalov, B. K. 2008. Who stands to lose from double-blind review? Nature, 452, 28.

Lane, D. 2008. Double-blind review: easy to guess in specialist fields. Nature, 452, 28.

Link, A. M. 1998. US and non-US submissions: an analysis of reviewer bias. Journal of the American Medical Association, 280, 246-247.

Naqvi, K. R. 2008. Double-blind review: the paw print is a giveaway. Nature, 452, 28.

O'Hara, B. 2008. Double-blind review: let diversity reign. Nature, 452, 28.

Tregenza, T. 2002. Gender bias in the refereeing process? Trends in Ecology \& Evolution, 17, 349-350.

Wennerås, C. \& Wold, A. 1997. Nepotism and sexism in peerreview. Nature, 387, 341-343. 